\title{
AB Blood Group Confers Higher Risk for Primary Brain Tumors in Pediatrics
}

\author{
Abdulrahman Al Shudifat \\ Hala Al Suqi ${ }^{2}$ \\ Kutada Soub ${ }^{\prime}$ \\ Leen Al Nemrawi ${ }^{2}$ \\ Moa'tasem Abu Jaber ${ }^{2}$ \\ Mohammad Al Barbarawi ${ }^{3}$ \\ Nour Shewaikani \\ Yazan El Adwan ${ }^{4}$ \\ Assem Al Refaei (D) ${ }^{2}$ \\ 'Department of Neurosurgery, \\ University of Jordan, Amman, Jordan; \\ ${ }^{2}$ School of Medicine, University of Jordan, \\ Amman, Jordan; ${ }^{3}$ Department of \\ Neurosurgery, Faculty of Medicine, \\ Jordan University of Science and \\ Technology, Irbid, Jordan; ${ }^{4}$ Jordan \\ Hospital, Amman, Jordan
}

Purpose: Our current study investigates the relationship between ABO blood groups and brain tumor incidence in the Jordanian pediatric population in a case-controlled manner.

Patients and Methods: This case-control study targeted pediatric primary brain tumor patients and tumor-free controls. Cases included patients younger than 18 when given a histologically confirmed diagnosis with a primary brain tumor, ascertained from two tertiary hospitals in Jordan. Controls were age- and gender-matched to cases and acquired from JUH pediatric clinics, with an exclusion for all patients with a personal history of tumors. Through using available records and calling guardians, our team obtained patients' and controls' blood groups.

Results: Our case control included $81(35.4 \%)$ pediatric primary brain tumor patients and age- and gender-matched tumor-free controls 148 (64.6\%). When compared to O blood group, patients with $\mathrm{A}$ and $\mathrm{B}$ blood groups were not at higher risk of developing pediatric primary brain tumors $(\mathrm{P}=0.742, \mathrm{P}=1.000$, respectively). However, Chi-square analysis revealed a 2.79-fold higher risk for pediatric primary brain tumors in $\mathrm{AB}$ blood group patients $(\mathrm{P}=0.024)$. Gender-specific analysis revealed a 3.42-fold higher risk for pediatric brain tumors in $\mathrm{AB}$ blood group males when compared to $\mathrm{O}$ blood group males.

Conclusion: This work represents the first published study on the association between blood groups and pediatric brain tumors. With future research with larger samples and control of confounding factors, $\mathrm{AB}$ blood group may become a more established risk factor for pediatric brain tumors, aiding in screening.

Keywords: pediatrics, children, brain tumors, ABO blood groups

\section{Introduction}

Brain tumors are the most common solid tumors in children, with an incidence rate ranging from 1.15 to 5.14 cases per 100,000 children-year. ${ }^{1,2}$ In Jordan, the incidence rate of pediatric primary brain tumors was 2.09 per 100,000 children-year. ${ }^{3}$ The various types of brain tumors include choroid plexus tumors, craniopharyngiomas, dysembryoplastic neuroepithelial tumors, germ cell tumors, pineal tumors, medulloblastomas and gliomas, with the latter two being the most common. As evidence of the seriousness of these diseases, medulloblastomas 5-year survival rate ranged between $50 \%$ and $60 \%{ }^{4,5}$ The situation is even worse regarding glioblastomas, which have a 13 to 73 months median survival a 5-year survival rate of less than $20 \%{ }^{6-13}$ As for those who will survive into their adulthood, they may face a significant long-term impairment to intellectual and neurological function. ${ }^{14}$

Potential risk factors for childhood brain tumors include familial syndromes and history, congenital anomalies, early infection exposure, advanced paternal age,
Correspondence: Assem Al Refaei

Jubaiha, Amman, I 1942, Jordan

Tel +962796553288

Email aas0170234@ju.edu.jo 
higher birth weight and head circumference at birth, radiation exposure and certain maternal medications. For instance, the use of CT scan to deliver a cumulative dose of 60 mGy tripled the risk of brain cancer. ${ }^{15}$ Regarding infection exposure, children of mothers who had a documented viral infection during pregnancy had an 11fold increased risk of a malignant nervous system tumor. ${ }^{16}$ In support, Krynska et al reported JCV DNA positivity in 11 of 23 medulloblastoma samples. ${ }^{17}$ Birth anomalies were also associated with a higher risk for medulloblastomas. ${ }^{18}$ Regarding maternal medications, antihypertensives, such as beta-blockers, diuretics, angiotensin-converting enzyme inhibitors and angiotensin receptor blockers, were associated with an increased risk of brain tumors in offspring. ${ }^{19}$

Although inconsistent, different $\mathrm{ABO}$ blood groups were also correlated with brain tumors. For example, blood group A conferred a higher risk for astrocytoma, glioblastoma and craniopharyngioma. ${ }^{20-22}$ Conversely, a prospective study of 107,472 participants revealed no association between blood group A and gliomas. ${ }^{23}$ Blood group $\mathrm{B}$, for its part, was the most common (56.1\%) blood group in central nervous system tumors in an Indian tertiary hospital. ${ }^{24}$ Except for Grade IV being more common in blood group B, Kumarguru et al identified Blood group $\mathrm{O}$ as the most common in patients with primary grade I, II and III CNS tumors. ${ }^{25}$ ABO blood groups were also investigated in the prognosis of brain tumors. In glioblastoma multiforme, one study found no association, whereas another revealed an independent poor prognostic value for non-O blood groups. ${ }^{26,27}$ Due to inconsistency and lack of any study over ABO blood groups effect over pediatric brain tumors, our current study aims to investigate the relationship between $\mathrm{ABO}$ blood groups and brain tumor incidence in the Jordanian pediatric population in a casecontrolled manner.

\section{Materials and Methods}

\section{Study Structure}

This study is a case-control study that included 81 pediatric primary brain tumor patients and 148 tumor-free controls. Patients under 18 years of age with a histologically confirmed diagnosis with a primary brain tumor were included. The study was held in Jordan University Hospital (JUH) and King Abdullah University Hospital (KAUH). Controls were matched parallel to cases' age and gender and acquired from JUH pediatric clinics, with an exclusion for all patients with a personal history of tumors. Through using available records and calling guardians, our team obtained patients' and controls' blood groups.

\section{Ethical Approval and Consent of Participants}

Ethical approvals were obtained from the Academic Research Council of the Faculty of Medicine at the University of Jordan, in accord with the ethical principles of the Helsinki Declaration. Verbal consent was obtained from all parents/legal guardians, as approved by the Academic Research Council of the Faculty of Medicine at the University of Jordan.

\section{Statistical Analysis}

The data was entered into a spreadsheet and analyzed using the IBM SPSS Statistics for Windows, version 22 (IBM Corp, Armonk, NY, USA). Descriptive statistics obtained included the mean and standard deviation for each variable measured. An independent $T$-test was used to investigate the relationship between age and brain tumor risk. Chi-square and odds ratio analysis was performed to evaluate the relationship between gender, ABO blood groups, and brain tumors risk. A significant level was set at 0.05 .

\section{Results}

\section{Sociodemographic Characteristics and} Blood Grouping of Cases and Controls

Our case control included $81(35.4 \%)$ pediatric primary brain tumor patients and $148(64.6 \%)$ tumor-free controls. Both groups were age- $(7.4 \pm 4.84$ vs $8.69 \pm 4.58$, respectively, $\mathrm{P}=0.053, t$-test $)$ and gender-matched $(\mathrm{P}=0.267$, Chisquare).

The distribution of $\mathrm{ABO}$ blood groups in cases and controls was $29.6 \%$ and $29.8 \%$ for A blood group, $12.3 \%$ and $14.2 \%$ for B blood group, $16 \%$ and $6.8 \%$ for $\mathrm{AB}$ blood group, and $42 \%$ and $43.9 \%$ for $\mathrm{O}$ blood group. Table 1 .

\section{Blood Grouping and Pediatric Primary Brain Tumors Risk}

When compared to blood group A, neither blood group B, $\mathrm{AB}$ or $\mathrm{O}$ had a difference in risk for pediatric brain tumors development $(\mathrm{P}=0.823$ ( $\mathrm{OR}=1.145), \mathrm{P}=0.089 \quad(\mathrm{OR}=0.42)$, and $\mathrm{P}=0.742 \quad(\mathrm{OR}=1.171)$, respectively, Chi-square $)$. 
Table I Characteristics of Children Diagnosed with Primary Brain Tumors and Controls

\begin{tabular}{|l|c|c|c|}
\hline Characteristics & Cases & Controls & $\begin{array}{c}\text { P value } \\
\text { (Odds Ratio) }\end{array}$ \\
\cline { 2 - 3 } & $\mathbf{( 8 1 )} \mathbf{n}(\%)$ & $\mathbf{( 1 4 8 )} \mathbf{n}(\%)$ & \\
\hline Sex & & & $0.267(1.416)$ \\
Male & $48(59.3)$ & $75(50.7)$ & \\
\hline Age at Diagnosis & $33(40.7)$ & $73(49.3)$ & \\
Mean (Standard Deviation) & $7.4(4.84)$ & $8.69(4.58)$ & \\
\hline Blood Group & & & \\
A & $24(29.6)$ & $44(29.8)$ & \\
B & $10(12.3)$ & $21(14.2)$ & \\
AB & $13(16)$ & $10(6.8)$ & \\
O & $34(42)$ & $65(43.9)$ & \\
\hline
\end{tabular}

Moreover, gender-specific comparisons revealed insignificant differences.

When compared to blood group B, neither blood group $\mathrm{AB}$ or $\mathrm{O}$ had a difference in risk for pediatric brain tumors development $\quad(\mathrm{P}=0.098 \quad(\mathrm{OR}=0.366)$, and $\mathrm{P}=1.000$ $(\mathrm{OR}=1.022)$, respectively, Chi-square). Moreover, genderspecific comparisons revealed insignificant differences.

When compared to O blood group, patients with A and $\mathrm{B}$ blood groups were not at higher risk of developing pediatric primary brain tumors $(\mathrm{P}=0.742, \mathrm{P}=1.000$, respectively, Chisquare). However, Chi-square analysis revealed a 2.79 -fold higher risk for pediatric primary brain tumors in $\mathrm{AB}$ blood group patients ( $\mathrm{P}=0.024$, Chi-square). Gender-specific analysis revealed insignificant differences except for $\mathrm{AB}$ blood group males who had a significantly higher risk of developing primary pediatric brain tumors when compared to $\mathrm{O}$ blood group males $(\mathrm{P}=0.042, \mathrm{OR}=3.42$, Chi-square). Table 2 .

\section{Discussion}

This work represents the first published study on the association between $\mathrm{ABO}$ blood groups and pediatric brain tumors.

Table 2 Comparison Between Blood Groups and Risk of Pediatric Brain Tumors

\begin{tabular}{|l|c|c|c|}
\hline \multirow{2}{*}{ Group } & A & B & AB \\
\cline { 2 - 4 } & P value (OR) & P value (OR) & P value (OR) \\
\hline A & - & $0.823(1.145)$ & $0.089(0.42)$ \\
B & $0.823(1.145)$ & - & $0.098(0.366)$ \\
$O$ & $0.742(1.171)$ & $1.000(1.022)$ & $\mathbf{0 . 0 2 4 ( 2 . 7 9 I )}$ \\
\hline
\end{tabular}

Note: ${ }^{A}$ Bold values are statistically significant.
ABO blood groups, discovered by Karl Landsteiner in 1901, proposed great value for transfusion medicine through blood compatibility testing and prevention of hemolytic reactions. ${ }^{28}$ However, more recent studies demonstrate a higher predisposition to certain diseases in certain $\mathrm{ABO}$ groups. Although inconsistently, these links were reported in numerous conditions, including nonalcoholic fatty liver disease, congenital heart disease, deep venous thrombosis, malaria severity, type 2 diabetes, and different cancers. ${ }^{29-34}$ Regarding brain tumors, non-O blood groups were repeatedly associated with increased risk and poor prognosis. ${ }^{24,25,27}$

In the current study, when compared to pediatric O blood group patients, AB group patients had a 2.79fold higher risk of developing primary brain tumors. This risk was further increased in male-specific analysis $(\mathrm{OR}=3.42)$. These findings oppose Koul et al study, in which $\mathrm{AB}$ blood group was not associated with a significant risk, but $\mathrm{B}$ blood group was. ${ }^{24}$ Moreover, inconsistent with previous findings, A group patients were not more susceptible to brain tumors. ${ }^{20-22}$

The findings of this study, when combined with other identified risk factors such as early-life exposure to ionizing radiation, may help in enhancing early detection and intervention. However, due to its observational nature, our case-control presents with strengths and weaknesses. One of the main strengths is being the first study to evaluate the effects of $\mathrm{ABO}$ blood groups on pediatric brain tumors. On the other hand, the main weakness of our study is the small sample size, along with the lack of more details, including tumor type, grade and outcomes, and lack of exclusion for possible risk factors. Accordingly, we recommend a larger sample size with more consideration of confounding factors and specifications in tumor types.

\section{Conclusion}

This work represents the first published study on the association between blood groups and pediatric brain tumors. With future research with larger sample sizes and control of confounding factors, $\mathrm{AB}$ blood group may become a more established risk factor for pediatric brain tumors, aiding in screening.

\section{Disclosure}

The authors report no conflicts of interest in this work.

\section{References}

1. McNeill KA. Epidemiology of brain tumors. Neurol Clin. 2016;34 (4):981-998. doi:10.1016/j.ncl.2016.06.014 
2. Subramanian SAT. Childhood brain tumors; 2020. Available from: https://www.ncbi.nlm.nih.gov/books/NBK535415/. Accessed September 24, 2021.

3. Tamimi AF, Tamimi I, Abdelaziz M, et al. Epidemiology of malignant and non-malignant primary brain tumors in Jordan. Neuroepidemiology. 2015;45(2):100-108. doi:10.1159/000438926

4. Frič R, Due-Tønnessen BJ, Lundar T, et al. Long-term outcome of posterior fossa medulloblastoma in patients surviving more than 20 years following primary treatment in childhood. Sci Rep. 2020;10 (1):9371. doi:10.1038/s41598-020-66328-8

5. David KM, Casey AT, Hayward RD, Harkness WF, Phipps K, Wade AM. Medulloblastoma: is the 5-year survival rate improving? A review of 80 cases from a single institution. J Neurosurg. 1997;86 (1):13-21. doi:10.3171/jns.1997.86.1.0013

6. Perkins SM, Rubin JB, Leonard JR, et al. Glioblastoma in children: a single-institution experience. Int J Radiat Oncol Biol Phys. 2011;80 (4):1117-1121. doi:10.1016/j.ijrobp.2010.03.013

7. Das KK, Mehrotra A, Nair AP, et al. Pediatric glioblastoma: clinico-radiological profile and factors affecting the outcome. Child's Nervous System. 2012;28(12):2055-2062. doi:10.1007/ s00381-012-1890-x

8. Faury D, Nantel A, Dunn SE, et al. Molecular profiling identifies prognostic subgroups of pediatric glioblastoma and shows increased YB-1 expression in tumors. J Clin Oncol. 2007;25(10):1196-1208. doi:10.1200/JCO.2006.07.8626

9. Nikitović M, Stanić D, Pekmezović T, et al. Pediatric glioblastoma: a single institution experience. Child's Nervous System. 2016;32 (1):97-103. doi:10.1007/s00381-015-2945-6

10. Adams H, Adams HH, Jackson C, Rincon-Torroella J, Jallo GI, Quiñones-Hinojosa A. Evaluating extent of resection in pediatric glioblastoma: a multiple propensity score-adjusted population-based analysis. Child's Nervous System. 2016;32(3):493-503. doi:10.1007/ s00381-015-3006-x

11. Mahvash M, Hugo HH, Maslehaty H, Mehdorn HM, Stark AM. Glioblastoma multiforme in children: report of 13 cases and review of the literature. Pediatr Neurol. 2011;45(3):178-180. doi:10.1016/j. pediatrneurol.2011.05.004

12. Broniscer A, Gajjar A. Supratentorial high-grade astrocytoma and diffuse brainstem glioma: two challenges for the pediatric oncologist. Oncologist. 2004;9(2):197-206. doi:10.1634/theoncologist.9-2-197

13. Stupp R, Mason WP, van den Bent MJ, et al. Radiotherapy plus concomitant and adjuvant temozolomide for glioblastoma. $N$ Engl $J$ Med. 2005;352(10):987-996. doi:10.1056/NEJMoa043330

14. Krull KR, Hardy KK, Kahalley LS, Schuitema I, Kesler SR. Neurocognitive outcomes and interventions in long-term survivors of childhood cancer. J Clin Oncol. 2018;36(21):2181-2189. doi:10.1200/JCO.2017.76.4696

15. Pearce MS, Salotti JA, Little MP, et al. Radiation exposure from CT scans in childhood and subsequent risk of leukaemia and brain tumours: a retrospective cohort study. Lancet. 2012;380 (9840):499-505. doi:10.1016/S0140-6736(12)60815-0

16. Fear NT, Roman E, Ansell P, Bull D. Malignant neoplasms of the brain during childhood: the role of prenatal and neonatal factors (United Kingdom). Cancer Causes Control. 2001;12(5):443-449. doi:10.1023/A:1011201524589

17. Krynska B, Del Valle L, Croul S, et al. Detection of human neurotropic JC virus DNA sequence and expression of the viral oncogenic protein in pediatric medulloblastomas. Proc Nat Acad Sci. 1999;96 (20):11519-11524.
18. Partap S, MacLean J, Von Behren J, Reynolds P, Fisher PG. Birth anomalies and obstetric history as risks for childhood tumors of the central nervous system. Pediatrics. 2011;128(3):e652-e657.

19. Houben MPWA, Coebergh JWW, Herings RMC, et al. The association between antihypertensive drugs and glioma. $\mathrm{Br} J$ Cancer. 2006;94(5):752-756. doi:10.1038/sj.bjc. 6603000

20. Zampieri P, Meneghini F, Grigoletto F, et al. Risk factors for cerebral glioma in adults: a case-control study in an Italian population. J Neurooncol. 1994;19(1):61-67. doi:10.1007/BF01051049

21. Allouh MZ, Al Barbarawi MM, Hiasat MY, Al-Qaralleh MA, Ababneh EI. Glioblastoma and ABO blood groups: further evidence of an association between the distribution of blood group antigens and brain tumours. Blood Transfus. 2017;15(6):543-547.

22. Mehrazin M. ABO blood group frequency and brain tumors. Asian Pacific J Cancer Prevent. 2006;7(4):582-584.

23. Cote DJ, Downer MK, Zoltick ES, Smith TR, Stampfer MJ. ABO blood group and risk of glioma. Neuro Oncol. 2017;19(6):871-873. doi:10.1093/neuonc/nox013

24. Koul RK, Ismail M, Mustafa SA, Ashraf A. Correlation of ABO/Rh blood groups with various malignancies at a tertiary hospital in Kashmir. Int J Sci Study. 2018;6(8):1-5.

25. Kumarguru BN, Pallavi P, Sunila Manjunath GV, Vasan TS, Rajalakshmi BR. Histopathological study of central nervous system lesions: emphasizing association of neoplasms with $\mathrm{ABO}$ blood groups. J Clin Diagn Res. 2017;11(4):Ec15-ec20.

26. Zeki Akca HM, Erden A, Buyukcelik A, Sezer EY, Inal A. The relationship between $\mathrm{ABO}$ blood group and glioblastoma multiforme. Med-Science. 2014;3(4):1639-1647. doi:10.5455/ medscience.2014.03.8160

27. Sokmen FC, Karacin C. Prognostic value of ABO blood groups in patients with glioblastoma multiforme. J Colle Physicians Surg Pak. 2020;30(7):713-716.

28. Bertsch T, Lüdecke J, Antl W, Nausch LWM. Karl Landsteiner: the discovery of the ABO blood group system and its value for teaching medical students. Clin Lab. 2019;65(6). doi:10.7754/Clin. Lab.2018.181218

29. Zhong GC, Liu S, Wu YL, et al. ABO blood group and risk of newly diagnosed nonalcoholic fatty liver disease: a case-control study in Han Chinese population. PLoS One. 2019;14(12):e0225792. doi:10.1371/journal.pone.0225792

30. Kuesap J, Na-Bangchang K. The effect of ABO blood groups, hemoglobinopathy, and heme oxygenase-1 polymorphisms on malaria susceptibility and severity. Korean J Parasitol. 2018;56(2):167-173. doi:10.3347/kjp.2018.56.2.167

31. Yu M, Wang C, Chen T, Hu S, Yi K, Tan X. ABO blood groups and risk of deep venous thromboembolism in Chinese Han population from Chaoshan region in South China. Saudi Med J. 2017;38 (4):396-399. doi:10.15537/smj.2017.4.16349

32. Zu B, You G, Fu Q, Wang J. Association between ABO blood group and risk of congenital heart disease: a 6-year large cohort study. Sci Rep. 2017;7:42804. doi:10.1038/srep42804

33. Meo SA, Rouq FA, Suraya F, Zaidi SZ. Association of ABO and Rh blood groups with type 2 diabetes mellitus. Eur Rev Med Pharmacol Sci. 2016;20(2):237-242.

34. Zhang BL, He N, Huang YB, Song FJ, Chen KX. ABO blood groups and risk of cancer: a systematic review and meta-analysis. Asian Pacific j Cancer Prevent. 2014;15(11):4643-4650. doi:10.7314/ APJCP.2014.15.11.4643 


\section{Publish your work in this journal}

Risk Management and Healthcare Policy is an international, peerreviewed, open access journal focusing on all aspects of public health, policy, and preventative measures to promote good health and improve morbidity and mortality in the population. The journal welcomes submitted papers covering original research, basic science, clinical \& epidemiological studies, reviews and evaluations, guidelines, expert opinion and commentary, case reports and extended reports. The manuscript management system is completely online and includes a very quick and fair peer-review system, which is all easy to use. Visit http://www.dovepress.com/testimonials.php to read real quotes from published authors.

Submit your manuscript here: https://www.dovepress.com/risk-management-and-healthcare-policy-journal 